\title{
Maternal and fetal outcome of heart disease in pregnancy: an audit in a tertiary hospital in India
}

\author{
Lalita Kambhampati, Kimaya A. Mali*, Meena N. Satia
}

Department of Obstetrics and Gynecology, KEM Hospital, Mumbai, Maharashtra, India

Received: 09 May 2019

Accepted: 09 July 2019

\section{*Correspondence:}

Dr. Kimaya A. Mali,

E-mail: drkimaya123@gmail.com

Copyright: (C) the author(s), publisher and licensee Medip Academy. This is an open-access article distributed under the terms of the Creative Commons Attribution Non-Commercial License, which permits unrestricted non-commercial use, distribution, and reproduction in any medium, provided the original work is properly cited.

\begin{abstract}
Background: There has been a rising incidence of pregnancy complicated by heart disease in India. The importance of heart disease in pregnancy lies in its high morbidity and mortality in both maternal and fetal outcomes combined with lack of enough established guidelines in its management.

Methods: A study was done in department of obstetrics and gynaecology, KEM hospital, Mumbai from January 2016 to April 2017 retro prospectively studying the different manifestations of heart disease in pregnancy and the maternal and fetal outcomes.

Results: During the study period, there were 6500 deliveries in the study center and of them 135 presented with heart disease. Of the 135 cases observed, 100 cases came under the inclusion criteria and were included in the study. The incidence of heart disease in pregnancy in the current institute is $2 \%$. In the 100 cases, $55 \%$ were seen to have rheumatic heart disease, $32 \%$ with cyanotic and acyanotic congenital heart disease and $13 \%$ with other conditions such as peripartum cardiomyopathy and mitral valve prolapse. Maternal outcome shows 44 patients delivered vaginally, 21 by assisted vaginal delivery and 35 required caesarean section. Maternal adverse cardiac events comprised of heart failure seen in 11 cases, ICU admissions required in 14 patients and maternal mortality in one case. Neonatal outcome comprised of 31 preterm births, still births 2, low birth weight seen in 41 and 16 needing NICU admissions.

Conclusions: Early diagnosis and prompt management with a multidisciplinary approach is fundamental in managing a case of heart disease in pregnancy.
\end{abstract}

Keywords: Fetal outcome, Heart disease, High-risk pregnancy, Manifestations of heart disease, Maternal outcome, Pregnancy

\section{INTRODUCTION}

Heart disease in pregnancy is one of the leading non obstetric causes of maternal mortality and is the leading cause of maternal intensive care unit admissions in the world. It complicates more than $1 \%$ of all pregnancies and an incidence of $3.1 \%$ in pregnancy. ${ }^{1}$ Heart disease accounts for $15 \%$ of pregnancy related mortality. ${ }^{1}$ Studies in western countries have shown that cardiovascular disease in pregnancy is now the leading cause of maternal death in pregnancy. ${ }^{2}$
According to a study conducted in India by Konar et al, prevalence of heart disease in pregnancy was 0.3 to $3 \%$ and incidence of heart failure was $7 \% .{ }^{3}$ Decompensation of heart disease leads to heart failure. In the study it was proven that early diagnosis and prompt treatment of heart failure reduced mortality by more than $50 \%$. The aim of this study was to see the incidence and different manifestations of heart disease in the present institution and to assess their effect on maternal and fetal outcome. Major cardiovascular events in mother and fetus were studied. 
Heart disease in pregnancy can be classified as the defects pertaining to rhythm disturbances, circulation disturbances like ischemic heart disease, valve pathology as seen in valvular heart disease. Recently an increased number of patients are presenting with peripartum cardiomyopathy which is a distinct form of cardiomyopathy seen in pregnancy. Most commonly observed heart disease in pregnancy is valvular heart disease which can be congenital or acquired. Congenital heart disease comprises commonly of atrial septal defect, ventricular septal defect, patent ductus arteriosus and cyanotic heart diseases like Tetralogy of Fallot.

Most common heart disease which is acquired is rheumatic heart disease. In our country, heart disease in pregnancy is mostly rheumatic heart disease with the predominant valvular lesion being mitral stenosis..$^{5}$ There can be an increase in prevalence of heart disease in teaching institutes than the overall population, this can be attributed to the fact that teaching institutes are not being the tertiary referral centers for high risk pregnancies. In developed countries congenital heart disease along with ischemic heart disease have a higher prevalence than rheumatic heart disease. This could be due to increasing age at marriage and an increased proportion of women with treated congenital heart disease entering reproductive age and also the near eradication of rheumatic fever and sequelae owing to improvement in living conditions and early detection of the disorder.

A gradual rise of peripartum cardiomyopathy has been observed over the past few years. Although the estimated number of cases is only $2-3$ in 10,000 pregnancies, it leads to increasing maternal morbidity and mortality observed in pregnancy. ${ }^{4}$

The physiological changes which occur in pregnancy due to increased metabolic demands of mother and fetus are responsible for worsening of pre-existing heart disease or its diagnosis in hitherto undiagnosed patients or the development of peripartum cardiomyopathy.

The major factors responsible physiologically are the increase in cardiac output and decrease in systemic vascular resistance. Cardiac output increases by $40 \%$ during pregnancy, half of which is seen by 8 weeks' gestation. Peak cardiac output is seen in second trimester itself and it fluctuates further peripartum. Heart rate increases from 20 weeks to 32 weeks which increases stroke volume due to the increase seen in both cardiac output and heart rate. There is a decrease in blood pressure due to active vasodilatation. There can be upto $30 \%$ increase in heart size. These physiological changes although necessary for survival of mother and fetus, may not always be well tolerated by women with pre - existing heart disease leading to worsening ventricular dysfunction and heart failure or may give rise to previously unknown heart disease. Anemia and preeclampsia which are commonly seen co morbidities in India, can precipitate heart failure leading to worsening prognosis of these women. NYHA status of the mother, specifically a worsening NYHA functional class can lead to increase in maternal morbidity and mortality. For women in NYHA class I or II symptoms, maternal mortality is $<1 \%$, and for class III or IV symptoms maternal mortality increases to $7 \%$. Fetal mortality rate is as high as $30 \%$ for women in NYHA class IV. ${ }^{5,6}$

Hence strict antepartum follow up and monitoring of NYHA grade and early diagnosis and treatment of co morbidities and complications are the need of the day.

\section{METHODS}

An observational, non-interventional, retro prospective study was conducted in KEM hospital, India in the department of obstetrics and gynaecology by the authors to study the incidence of heart disease in pregnancy in patients presenting to or being referred to a tertiary care center in India like the institution of study. The different manifestations of heart disease in the women like valvular heart disease including congenital or acquired and cardiomyopathy was studied. The different valvular heart diseases studied were congenital heart disease like septal defects, patent ductus arteriosus, bicuspid aortic valve, Tetralogy of Fallot and acquired heart diseases which included rheumatic heart disease and mitral valve prolapse. The different comorbidities seen in women suffering from heart disease and the different complications observed were studied. The maternal outcome was seen as mode of delivery and the maternal adverse cardiac events were noted. Perinatal outcome was observed as perinatal adverse events like low birth weight, prematurity, still birth or stay in intensive care units. All pregnant women diagnosed with cardiac disease, either preexisting or diagnosed anytime in the antepartum or within 6 weeks postpartum were included in the study after 28 weeks of gestation. Patients who had early pregnancy loss or medical termination of pregnancy were not included.

Study was commenced after approval from the institutional ethics committee. All the registered, unregistered and transferred patients presenting to the center of study in the period between January 2016 to April 2017, who were willing to participate in the study and who fulfilled the inclusion criteria were enrolled after taking an informed consent. Sample size was calculated as per available medical records which showed 135 women presenting to the study center with heart disease within the study period, of them 100 women fulfilled the inclusion criteria and were enrolled into the study.

The study is an observational, cross sectional study where the objective was not to compare between two groups or to find any association between risk factors and outcome. Hence, descriptive statistics i.e. percentages and proportions were calculated wherever necessary and no statistical test has been applied. 
All women who were registered in the study center were called at least once a month in the first two trimesters, twice weekly up to 32 weeks and weekly from 36 weeks. Echocardiography was done for all women on confirmation of pregnancy and repeated if any symptoms of worsening heart disease were noticed. Co morbidities like anemia, infections, diabetes and pre-eclampsia were all screened for and treated promptly if identified. Pregnant women were evaluated by both obstetricians and cardiologists regularly. Mode of delivery was planned in a multi-disciplinary approach by cardiologists, obstetricians and anesthesiologists together. Caesarean section was planned only for obstetric indications, the only exception being a case of Takayasu arteritis which was scheduled for an elective caesarean section. Close monitoring was done as soon as labor commenced, extending into the immediate postpartum period. Fluid monitoring was of utmost importance and was done depending on the type of cardiac lesion. Infective endocarditis prophylaxis was given where indicated..

\section{RESULTS}

\section{The results observed in the above study were as follows}

Total number of deliveries in 15 months was 6500 of which 135 patients were diagnosed with heart disease (either newly diagnosed or preexisting).

Incidence of heart disease hence was $2 \%$ for the above study period in the tertiary center where the study was conducted. Of the 135 cases of heart disease observed 100 came under our present inclusion criteria.

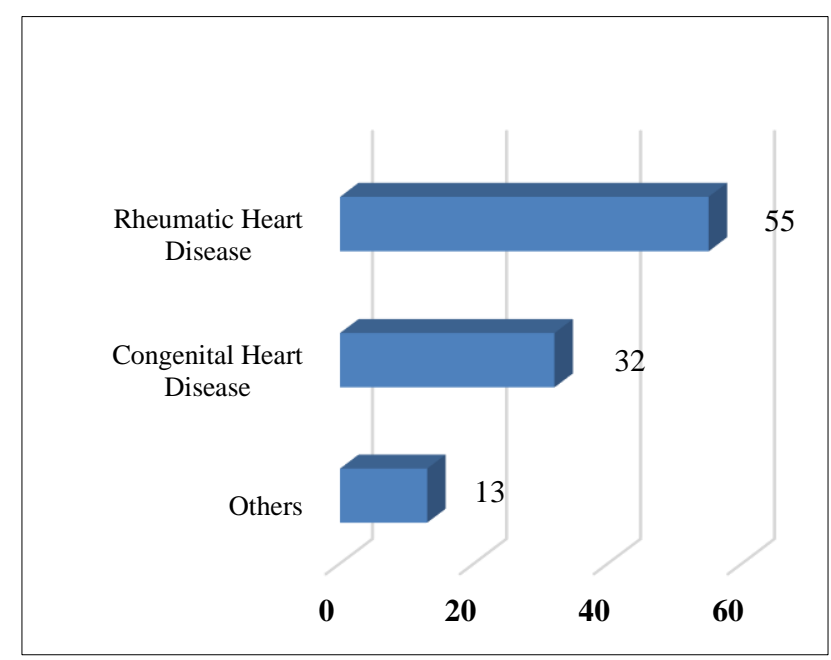

Figure 1: Manifestations of heart disease.

Congenital heart disease was seen in 32 and rheumatic in 55. Other disorders like mitral valve prolapse and cardiomyopathy were seen in 13 .

Of the 100 patients in the study, 6 patients were completely unregistered and were diagnosed with heart disease in the antepartum period due to development of
NYHA class 2 or 3 dyspnea or heart failure. 50 were registered in the first or second trimester with regular antenatal consultation with obstetrician and cardiologist. $2 \mathrm{D}$ echo was done for all of them after conception and was repeated on worsening dyspnea, increasing murmur intensity or suspicion of heart failure. 44 patients were referred to the tertiary center and trans thoracic echocardiogram was done antenatally in all the patients where possible except those who presented in active labor.

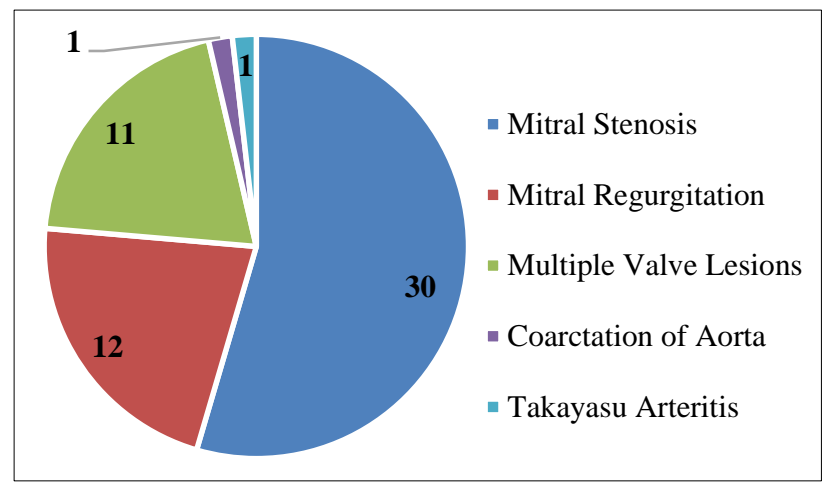

Figure 2: Rheumatic disease.

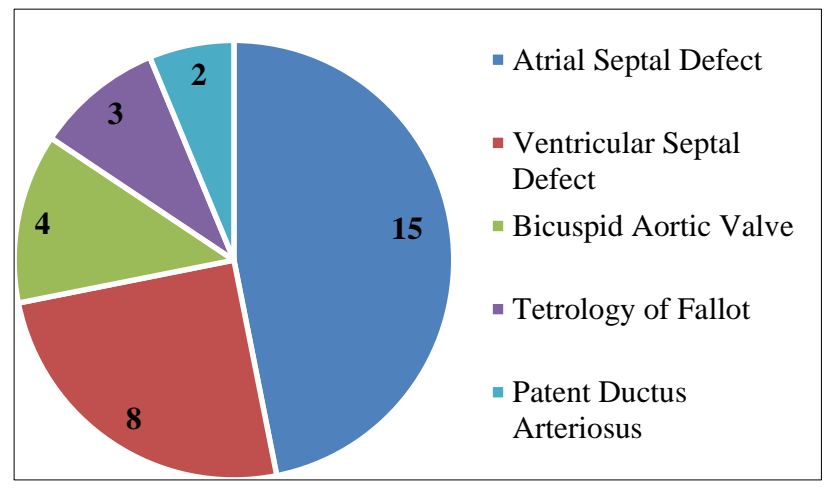

Figure 3: Congenital heart disease.

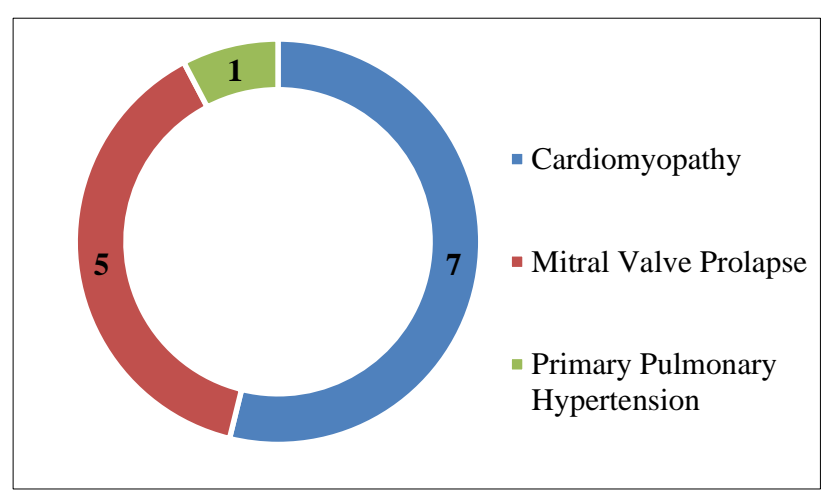

Figure 4: Others.

Congenital heart disease in mother can lead to an increased risk of fetal cardiac diseases which is $3-5 \%$ as compared to normal population. Hence, fetal echocardiography was done in all booked patients with congenital heart disease. Out of 20 fetal 
echocardiography performed, 3 were diagnosed with fetal cardiac disease.

47 out of 100 cases under study were diagnosed during pregnancy.

Cardiac interventions were required in 42 cases of which 29 were required during pregnancy or in the immediate postpartum period.

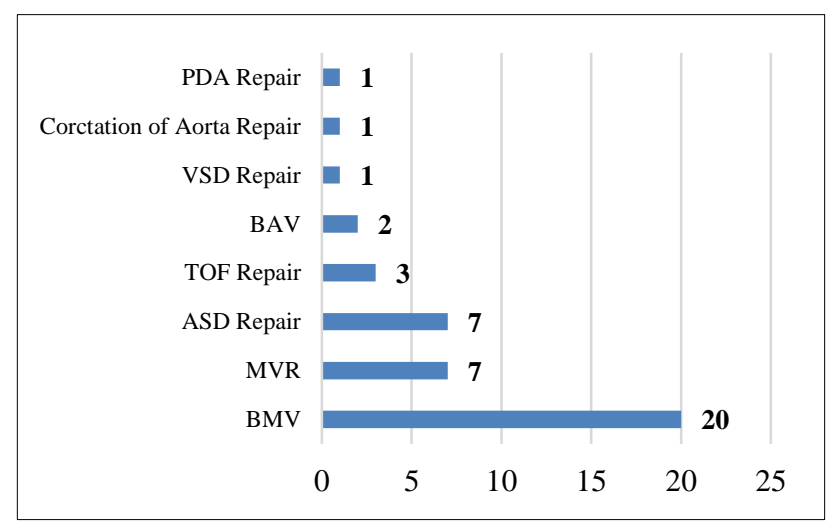

Figure 5: Cardiac interventions done before or during pregnancy.

Prolonged admission to the hospital was required in 42 in the 100 pregnancies. The reasons for admissions were varied. They comprised of evaluation of heart disease, treatment of any co morbidities, evaluation and management of any complications which arose and anticoagulant administration and its monitoring.

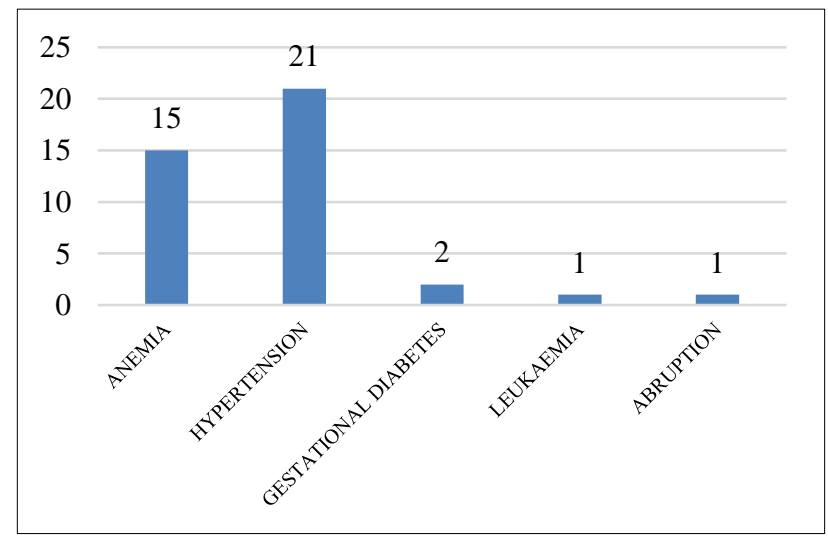

Figure 6: Co-morbidities seen.

Anticoagulation was required in 19 patients. If the heart disease was pre existing and preconceptional counselling was possible then conversion from warfarin to low molecular weight heparin or Uncojugated heparin was done prior to pregnancy and continued till second trimester when conversion to warfarin is done. In third trimester, warfarin was again discontinued and Heparin was preferred which was stopped 6 to 12 hours prior to delivery.

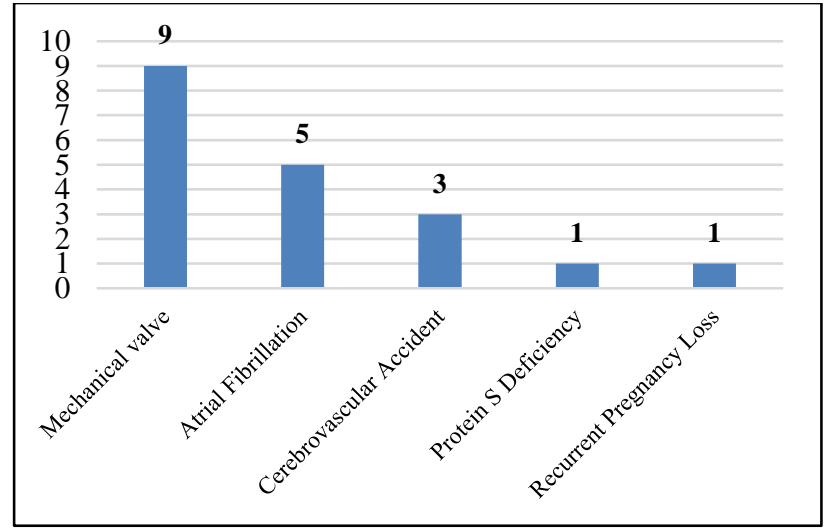

Figure 7: Reasons for anticoagulation.

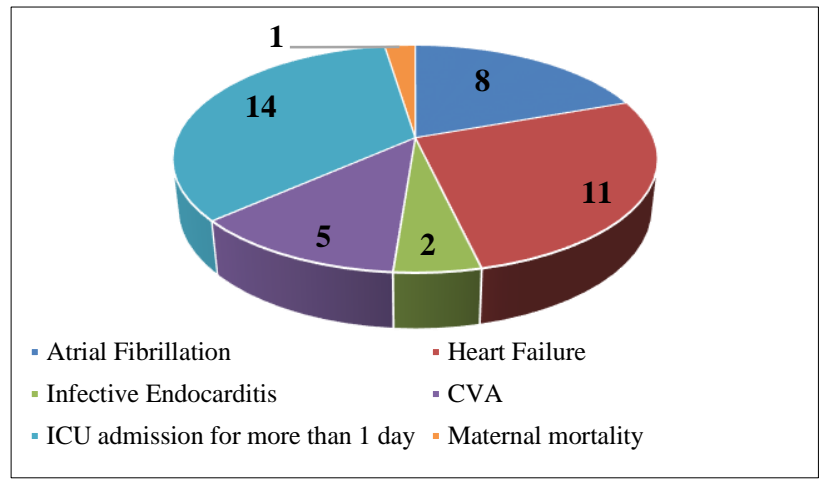

Figure 8: Maternal adverse events.

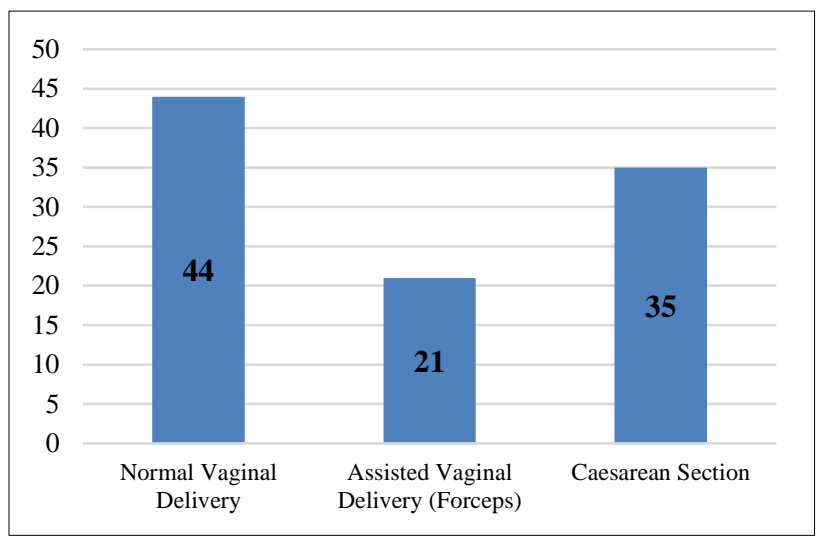

Figure 9: Maternal outcome (mode of delivery).

\section{Maternal adverse events}

Rhythm disturbances: 8 cases were seen to develop atrial fibrillation.

Heart failure was seen in 11 patients. 7 in antenatal period and 4 in perinatal. Of these 5 were complicated by atrial fibrillation, 5 with anemia and 2 by hypertension.

Cerebrovascular accidents in 5 patients, myocarditis leading to maternal mortality in 1 , infective endocarditis in 1. ICU admission for more than one day was required in 14 cases. 


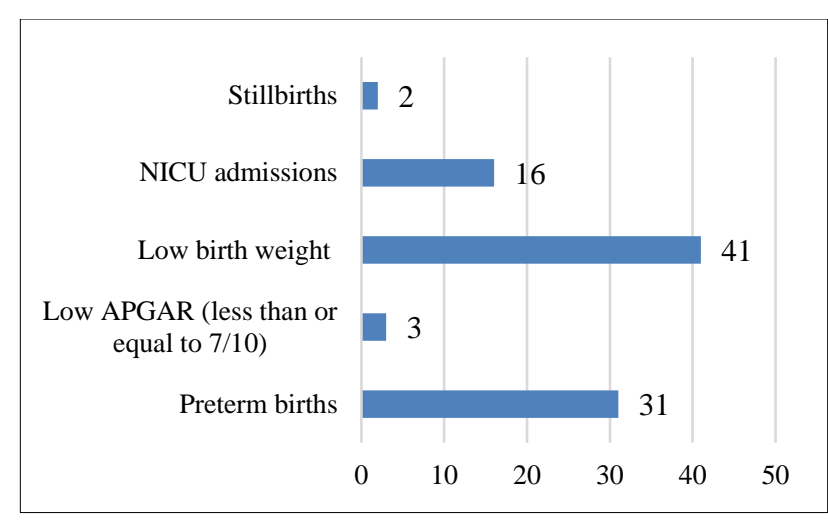

Figure 10: Neonatal outcome.

Induction was required in 10 patients and all for obstetric reasons.

35 Caesarean sections of which only one was due to Takayasu arteritis rest due to obstetric reasons. Forceps delivery done in 21 and vaginal delivery in 44 .

\section{DISCUSSION}

The changing trends of socio-economic status with improved medical care have resulted in more women presenting with treated congenital heart disease in India. Simultaneously, increasing urbanization, rapid population growth and overcrowding has resulted in increasing population of women with rheumatic heart disease. This has resulted in a rise in cardiovascular diseases in pregnancy. The myriad cardiac conditions observed along with limited in-depth knowledge and established guidelines on their management during pregnancy prompted this study. Case to case basis consideration was given in the management of each patient. Although routine antibiotic prophylaxis is not advocated during delivery by the 2008 American heart association, it was administered in the present institute, as the majority of the population of study hailed from a poorer socioeconomic stratum.

Table 1: Comparison of manifestations of heart disease.

\begin{tabular}{|c|c|c|c|c|}
\hline Study & Total cases & $\begin{array}{l}\text { Rheumatic } \\
\text { heart disease }\end{array}$ & $\begin{array}{l}\text { Congenital } \\
\text { heart disease }\end{array}$ & Others \\
\hline Avila et $\mathrm{al}^{8}$ & 1000 & $55 \%$ & $19 \%$ & $\begin{array}{l}26 \% \text { (Coronary heart disease, } \\
\text { cardio myopathy, rhythm disturbances) }\end{array}$ \\
\hline Salam et $\mathrm{al}^{9}$ & 90 & More than $50 \%$ & Less than $20 \%$ & $20 \%$ \\
\hline Our study & 100 & $55 \%$ & $32 \%$ & $\begin{array}{l}13 \% \text { (Cardiomyopathy, mitral valve } \\
\text { prolapse, rhythm disturbances) }\end{array}$ \\
\hline
\end{tabular}

Table 2: Comparison of mode of delivery.

\begin{tabular}{|llll|}
\hline & Vaginal delivery & Instrumental delivery (Forceps) & Caesarean section \\
\hline Our study & $43 \%$ & $22 \%$ & $35 \%$ \\
\hline Puri et al ${ }^{14}$ & $37 \%$ & $8 \%$ & $38 \%$ \\
\hline
\end{tabular}

In this study it is seen that the incidence of heart disease in the population under study during the specified time period was $2 \%$ which is consistent with other studies conducted in India in recent times. In the western countries' studies have shown a prevalence of 0.2 to $4 \% .^{7}$

Echocardiography was done for all patients with suspected murmurs and symptoms of breathlessness, chest pain and palpitations. Echocardiography screening in all women with suspected heart disease led to earlier and more accurate diagnosis of valvular heart disease and peripartum cardiomyopathy.

In western countries incidence of congenital heart disease and ischemic heart disease is higher than valvular heart disease caused by rheumatic heart disease. ${ }^{10}$ This can be achieved by effective diagnosis and early intervention in all cases of rheumatic fever which is an auto immune and inflammatory disorder occurring after upper respiratory tract infection caused by group A streptococcus leading to permanent damage to the valves of the heart. Another factor which decreased incidence of rheumatic factors was social improvement by prevention of overcrowding and improved hygiene in living conditions.

42 patients in the study had cardiac interventions done and of that 29 were done during pregnancy. $13 \%$ had repairs done for congenital heart lesions prior to pregnancy. $29 \%$ had repairs done for rheumatic heart disease. $20 \%$ had the repairs done prior to planning conception but $9 \%$ required intervention during pregnancy mostly due to severe valvular lesions predisposing to heart failure. $20 \%$ had balloon mitral valvuloplasty. In valves deemed unfit for valvotomy and 
in cases of restenosis after BMV, valve replacement was done in $9 \%$.

Maternal mortality due to surgical intervention done during pregnancy is comparable to cardiac surgery done in non-pregnant state but neonatal mortality is increased. The $2 \%$ still births observed in our study occurred in mothers who underwent valve replacement during pregnancy due to extreme preterm labor which occured within a day of surgery. Hence surgical correction of cardiac lesions in pregnancy is only recommended when all other interventions fail. Ideal period for surgery is 13 to 28 weeks of gestation. In cases where surgery is planned after the period of viability (28 weeks in India), corticosteroids are recommended 24 hours prior to surgery. ${ }^{11-13}$

Table 3: Maternal cardiac adverse events.

\begin{tabular}{|lllll|}
\hline & Heart failure & Arrythmia & Thromboembolism & Infective endocarditis \\
\hline Our study & $11 \%$ & $9 \%$ & $5 \%$ & $2 \%$ \\
\hline Avila et $\mathrm{al}^{8}$ & $12 \%$ & $6 \%$ & $2 \%$ & $0.5 \%$ \\
\hline Konar et $\mathrm{al}^{3}$ & $7.4 \%$ & $5.3 \%$ & $0.3 \%$ & $0.3 \%$ \\
\hline
\end{tabular}

Table 4: Maternal mortality.

\begin{tabular}{|c|c|c|c|}
\hline Our study & Konar et $\mathrm{al}^{3}$ & Salam et $\mathbf{a l}^{9}$ & A vila et $\mathbf{a l}^{8}$ \\
\hline $1 \%$ & $1.1 \%$ & $4.4 \%$ & $2.7 \%$ \\
\hline
\end{tabular}

Mode of delivery in the present study was predominantly spontaneous vaginal delivery. $10 \%$ were induced with Dinoprostone gel, all for obstetric indications. Vaginal delivery was done in $43 \%$ and instrumental delivery using forceps was done in $22 \%$. Caesarean section was done in $35 \%$ of which only one was due to Takayasu arteritis with uncontrolled hypertension in first stage of labor. Similar results were seen in a study conducted in Punjab by Puri et al, where vaginal delivery was done in $37 \%$, Forceps in $8 \%$, lower caesarean section was done in $38 \%$ and all for obstetric indications. ${ }^{14}$

Several factors are considered when induction of labor is planned in patients with heart disease which include Bishop's score, maternal and fetal condition and the method of induction. Duration of induction interval is to be monitored closely as a long duration is to be avoided especially if the cervix is unfavorable. Although there are no absolute contraindications to induction of labor using prostaglandins, Dinoprostone has a more persistent effect on systemic vascular resistance which can be detrimental in patients with cyanosis hence mechanical methods of induction with Foleys catheter is preferred in such cases.

Mode of delivery should be individualized on a case to case basis. Delivery plan should be decided with a multidisciplinary approach involving obstetrician, cardiologist, anesthesiologist and neonatologist and should consist of mode delivery with the type of anesthesia, level of monitoring required during delivery and special considerations during delivery like fluid monitoring.

Vaginal delivery is preferred in most cases as mode of delivery with instrumental delivery to cut short second stage of labor, as caesarean delivery causes more blood loss, more risk of infection and thromboembolism. ${ }^{15}$ Cesarean delivery is generally done only for obstetric indications (like in the present study), except in cases of preterm labor in women on warfarin, Marfan syndrome with aortic diameter $40-45 \mathrm{~mm}$, and intractable heart failure. $^{16}$

Anticoagulation was required during pregnancy by $19 \%$ women in the present study. $9 \%$ had mechanical valves, $5 \%$ had atrial fibrillation and 3\% with history of cerebrovascular events and $2 \%$ with miscellaneous causes like recurrent pregnancy loss and protein $\mathrm{S}$ deficiency. The preferred anticoagulant differed according to period of gestation and the tolerance of the patient.

Anticoagulation was given in women who had undergone valve replacement with artificial valves, with history of atrial fibrillation or thromboembolic phenomenon. When anticoagulation is started before pregnancy oral anticoagulants are preferred and they are changed to low molecular heparin when conception is planned.

Although more studies are indicated to confirm the findings, recent studies have shown low molecular weight Heparin to have minimal deleterious effects on the fetus with a more stable and predictive anticoagulation. The thromboprophylactic effect was, however, dependent on whether the recommended therapeutic levels were achieved. In the study all $19 \%$ women had uneventful antepartum and peripartum periods with no adverse effects on the fetus. ${ }^{17}$

Co morbidities observed in the patients diagnosed with heart disease were hypertension $21 \%$, anemia $15 \%$ and 
gestational diabetes $2 \%$. The main concern in these women is to prevent precipitation of heart failure and strict monitoring for early detection and management of the same. Maternal mortality in the current study was $1 \%$ which was same as observed in the multi centric study conducted in India by Konar et al, and in Devabhaktuni et al. ${ }^{3,18}$

In majority of cases maternal mortality can be prevented by pre conceptional counseling, risk stratification and antenatal and perinatal management in a tertiary care center. As per experience in other studies in similar centers, maternal mortality and morbidity was largely preventable due to these steps. This requires collaboration between cardiologist and obstetrician. Risk assessment can be done by disease specific series like the WHO risk stratification model. Further modification of risk stratification can be done by adding predictors which have been identified in large population studies like CARPREG risk score and ZAHARA study. Women who belong to WHO class IV should be advised against pregnancy but if diagnosed in pregnancy then more frequent antenatal checkups are required. In women classified as WHO class I or II routine antenatal checkup once a month till third trimester followed by weekly visits is sufficient.

Neonatal complications seen in maternal heart disease range from intrauterine growth restriction, preterm births, low birth weight and prolonged ICU stay, and these are seen in $20-28 \%$ of pregnancies complicated by heart disease and perinatal mortality is seen in $1-4 \% .{ }^{10}$ Similar results were found in our study also except for a higher rate of low birth weight - 40\%. This indicates the requirement of strict antepartum and intrapartum fetal assessment. Antepartum fetal assessment is done by different methods in the three trimesters. The essential component in first trimester is accurate dating for assessment of gestational age. Early assessment for congenital anomalies and fetal 2D echo is to be done especially in cases of congenital heart disease in mother so as to allow medical termination of pregnancy. After 28 weeks' gestation Doppler velocimetry can be done to assess the fetal condition and weekly or biweekly non stress test in third trimester. Continuous fetal monitoring is recommended during labor.

Finally, contraception plays a very important role in management of women with cardiovascular disorders. Unfortunately, there's no single best method for contraception and it should be individualized in each case after extensive counseling of the couple. Combined oral contraceptives are not preferred in women with cardiac disease due to increased risk of thrombotic complications. The progesterone only pill which is recommended in severe heart disease is 'Cerazette' containing Desogestrel. Although Depot-medroxyprogesterone acetate (DMPA) has a mild increase in fluid retention, it is not shown to be statistically significant and hence can be used. Barrier contraception with levonorgestrel containing intrauterine device or a dermal implant seems to be the best available options for long term reversible contraception.

The 2008 AHA and NICE guidelines do not recommend antibiotic prophylaxis before IUD insertion but rising incidence of endocarditis and high prevalence of PID in India necessitate antibiotic prophylaxis (ampicillin $2 \mathrm{~g}$ and gentamicin $80 \mathrm{mg}$ given IV 1 hour before IUCD insertion) especially in high risk conditions like prosthetic valves. Sterilization, both male and female, is a viable option in women who completed the family. Male sterilization is very effective but remains controversial due to shorter life expectancy of the female partner and potential for remarriage. Abdominal and laparoscopic tubal ligation can be performed in women with heart disease. Intracaesarean tubal ligation is desirable in women who completed their family due to lack of additional anesthesia risk. Emerging studies have shown hysteroscopy guided sterilization (Essure) to be a less risky option. ${ }^{19}$

\section{CONCLUSION}

The incidence of heart disease observed was $2 \%$. Mortality was seen in only one person in 100 cases studied. This was due to high index of suspicion, early diagnosis and prompt management. A multi-disciplinary approach with cardiac, obstetric, medical, anaesthetic and neonatologist tailored to meet individual needs of the patient can go a long way in preventing maternal and perinatal morbidity and mortality.

Among the south-east Asian countries, India has the highest global prevalence of rheumatic heart disease accounting to $27 \%$ of all cases globally according to WHO global health estimate 2015. Socioeconomic and environmental factors lead to increased incidence of rheumatic heart disease in India. The magnitude of the burden of heart disease can be significantly decreased by improving the socioeconomic status of people in this country. Hence it is not only medical attention but improved legislature and political will which can improve the high maternal morbidity and mortality caused by RHD.

Funding: No funding sources

Conflict of interest: None declared

Ethical approval: The study was approved by the Institutional Ethics Committee

\section{REFERENCES}

1. Nanna M, Stergiopoulos K. Pregnancy complicated by valvular heart disease: J Am Heart Assoc. 2014;3(3):e000712.

2. Khairy P, Ionescu-Ittu R, Mackie AS, Abrahamowicz M, Pilote L, Marelli AJ. Chan- ging mortality in congenital heart disease. J Am Coll Cardiol. 2010;56(14):1149-57. 
3. Konar H, Chaudhuri S. Pregnancy complicated by maternal heart disease: a review of 281 women. J Obstet Gynaecol India. 2012;62(3):301-6.

4. Pearson GD, Veille JC, Rahimtoola S, Hsia J, Oakley CM, Hosenpud JD, et al. Peripartum cardiomyopathy: National Heart, Lung, and Blood Institute and Office of Rare Diseases (National Institutes of Health) workshop recommendations and review. JAMA. 2000;283(9):1183-8.

5. Siu SC, Sermer M, Colman JM, Alvarez AN, Mercier LA, Morton BC, et al. Prospective multicenter study of pregnancy outcomes in women with heart disease. Circulation. 2001;104(5):515-21.

6. Drenthen W, Pieper PG, Roos-Hesselink JW, van Lottum WA, Voors AA, Mulder BJ, et al. Outcome of pregnancy in women with congenital heart disease: a literature review. J Am Coll Cardiol 2007;49(24):2303-11.

7. Weiss BM, von Segesser LK, Alon E. Outcome of cardiovascular surgery and pregnancy: a systematic review of the period 1984-1996. Am J Obstet Gynecol. 1998;179(6):1643-53.

8. Avila WS, Rossi EG, Ramires JA, Grinberg M, Bortolotto MR, Zugaib M. Pregnancy in patients with heart disease: Experience with 1,000 cases. Clin Cardiol. 2003;26(3):135-42.

9. Salam S, Mushtaq S, Mohi-ud-din K, Gul I, Ali A. Maternal and fetal outcome in pregnancy with heart disease in tertiary care hospital in India. Int J Reprod Contracept Obstet Gynecol. 2017;6(9):3947-51.

10. Siu SC, Sermer M, Colman JM. Prospective multicenter study of pregnancy outcome in women with heart disease. Circulation. 2001;104(5):51521.

11. Weiss BM, von Segesser LK, Alon E, Seifert B, Turina MI. Outcome of cardiovas- cular surgery and pregnancy: a systematic review of the period 1984 1996. Am J Obstet Gynecol. 1998;179(6):1643-53.

12. Chambers CE, Clark SL. Cardiac surgery during pregnancy. Clin Obstet Gynecol. 1994;37(2):316-23.

13. Becker RM. Intracardiac surgery in pregnant women. Ann Thorac Surg. 1983;36:453-8.

14. Puri S, Bharti A, Puri S, Mohan B, Bindal V, Verma $\mathrm{S}$. Maternal heart disease and pregnancy outcomes. JK Sci. 2013;15(1):7-10.

15. Bonanno C, Gaddipati S. Mechanisms of hemostasis at cesarean delivery. Clin Perinatol. 2008;35(3):53147.

16. Vahanian A, Baumgartner H, Bax J, Butchart E, Dion R, Filippatos G, et al. Guidelines on the management of valvular heart disease: the Task Force on the Management of Valvular Heart Disease of the European Society of Cardiology. Eur Heart J. 2007;28(2):230-68.

17. Abildgaard U, Sandset PM, Hammerstrom J, Gjestvang FT, Tveit A. Management of pregnant women with mechanical heart valve prosthesis: thromboprophylaxis with low molecular weight heparin. Thromb Res. 2009;124(3):262-7.

18. Devabhaktuni P, Devinenik K, Vemuri U. Pregnancy outcome in chronic rheumatic heart disease. J Obstet Gynaecol India. 2009;59(1):41-6.

19. Centers for Disease Control and Prevention (CDC). U S. Medical Eligibility Criteria for Contraceptive Use, 2010. MMWR Recomm Rep. 2010;59(RR-4):186.

Cite this article as: Kambhampati L, Mali KA, Satia MN. Maternal and fetal outcome of heart disease in pregnancy: an audit in a tertiary hospital in India. Int J Reprod Contracept Obstet Gynecol 2019;8:298390. 